\title{
Socio-economic Characteristics of Family-run Maize Farm in the Centre Region of Cameroon
}

\author{
Eloundou Etoundi Christian", *, Fon Dorothy Engwali², Minkoua Nzie Jules René3 \\ ${ }^{1}$ Department of Rural Socio-Economics and Agricultural Extension, Faculty of Agronomy and Agricultural Sciences, University of Dschang, \\ Dschang, Cameroon \\ ${ }^{2}$ Department of Agribusiness, Faculty of Economics and Management, University of Dschang, Dschang, Cameroon \\ ${ }^{3}$ Department of Economics and Management, Faculty of Social and Management Sciences, University of Buea, Buea, Cameroon
}

\section{Email address:}

elouetchristian@gmail.com(E. E. Christian),dengwali@yahoo.fr(F. D. Engwali),minkouarene@yahoo.fr_(M. N. J. René)

*Corresponding author

\section{To cite this article:}

Eloundou Etoundi Christian, Fon Dorothy Engwali, Minkoua Nzie Jules René. Socio-economic Characteristics of Family-run Maize Farm in the Centre Region of Cameroon. American Journal of Agriculture and Forestry. Vol. 9, No. 4, 2021, pp. 227-232.

doi: 10.11648/j.ajaf.20210904.19

Received: July 1, 2021; Accepted: July 12, 2021; Published: July 19, 2021

\begin{abstract}
This work presents the elements that characterise the socio-economic life of family maize farms. The research method was based on field surveys. The study was carried out between September 2019 and December 2020 in centre region of Cameroon. Data was collected through face-to-face interviews with 1060 (545 women and 515 men) maize farm managers who were selected in a reasoned manner using the snowball method based on the file of the Ministry of Agriculture and Rural Development of Cameroon. Data from the study was analysed using descriptive statistics. The results revealed that maize cultivation is mainly done by women, although women do not control the produce from these farms when they are married. $70.1 \%$ of the respondents are over 35 years old, $50 \%$ of the maize producers live in households with 4 to 8 people. Forty (40) percent of the respondents are in common-law unions without companies, but $73.9 \%$ of the respondent's state that their main activity is farming and $13.6 \%$ state that they are engaged in "other" activities. The level of education of the maize farmers is low and $13.9 \%$ said they had never been to school for several reasons. However, the $21.5 \%$ of respondents who rent land do so from indigenous people who have customary rights to the land but whose rental principles prohibit the establishment of perennial crops. The characteristics of family maize farms in Central Cameroon predispose them to unprofitable and inefficient agriculture. Producers are limited by their social conditions to make the farms evolve over time.
\end{abstract}

Keywords: Family, Main Activity, Maize Producers, Social Conditions

\section{Introduction}

In Cameroon, the agricultural sector is the main engine of economic growth in rural areas. This sector contributed $22.8 \%$ of the Gross Domestic Product (GDP) in 2015. In 2014, Cameroon recorded a growth rate of $5.9 \%$ of its Gross Domestic Product (GDP). The contribution of the primary sector to this GDP is $4.7 \%$, of which $4.1 \%$ for agriculture and $5.7 \%$ for livestock [1]. Agriculture is therefore the main provider of employment, with around $60 \%$ of the working population working on family farms. It also plays an irreplaceable role in income generation in the countryside[1,2].
Despite this significant position of agriculture, Cameroon, like all countries in the South, faced the "hunger riots" of 2008, caused by the sharp rise in food prices on the international market due to poor harvests [3]. The prices of necessities soared by $8.3 \%$ and $10.5 \%$ respectively in 2008 and 2009 , i.e. an increase of nearly $20 \%$ in two years [4]. However, the effects of this increase in food prices were accentuated by the fragility of agricultural systems and the precariousness of the resources of Africa's rural populations [3].

In response to this price fluctuation, farmers have had to develop strategies to move away from the family farm model to a business model [5]. This is not only about producing for the family's own consumption, but also about selling a large 
part of the production to cover other family expenses. The development of subsistence agriculture in Cameroon is led by Family Farming (FF). These are subject to numerous constraints [6] that prevent the head of a family farm from earning sufficient and necessary monetary income from his production to meet the vital needs of his family and to mobilise sustainable management methods nutrition, health and schooling of the children in the household.

However, as poverty is unevenly distributed in the regions of Cameroon, family maize farms in the Centre region have benefited from substantial institutional support such as: the elaboration of agricultural development strategies, access to factors of production, access to markets, and the development of capacities to negotiate, be informed and trained in order to facilitate the availability and accessibility of this cereal to the final consumer.

Despite this support from the public authorities in the maize sector, the price per kilogram of this crop reached 358 CFA francs in the second half of 2010 [7], although its price is generally around $120 \mathrm{CFA}$ francs during periods of intense production. This price volatility is certainly due to the rise in the price of inputs (fertilisers and phytosanitary products), but for Mabah et al, [8]it is the consequence of low productivity of farms in general and that of maize in particular, with less than 2 t. ha- 1 in the combined cropping systems of small family farms, around 2.5 tonnes per hectare in semi-intensive cultivation and 4.5 tonnes per hectare in large farms with improved varieties. The Centre Region is thus ranked 9th out of the 10 regions in Cameroon in terms of yield according to the PIDMA [9]. This low productivity is also a function of the different actors of family farms who have to combine resources and the different support received, even though they have different socio-economic characteristics in the Centre Region to improve their living conditions.

\section{Methodology}

The study was carried out in the central region, which extends between $2^{\circ} 47^{\prime}$ and $6^{\circ} 5^{\prime}$ north latitude and between $11^{\prime} 40$ and $14^{\circ}$ east longitude, over a continental area of $68,953 \mathrm{~km}^{2}$. It borders the Adamawa region (to the north), the southern region (to the south), the western region (northwest), the coastal region (south-west) and the eastern region (east) as shown in Figure 1. The research method was based on field surveys in which primary data were collected using a well-structured questionnaire through interviews with heads of family farms.

\subsection{Study Population}

The study population is made up of all the maize producers in the central region identified by the deconcentrated services of the Ministry of Agriculture and Rural Development. Among these producers, the analysis unit was the head of the farm because it is the latter who controls resources and plans operations.

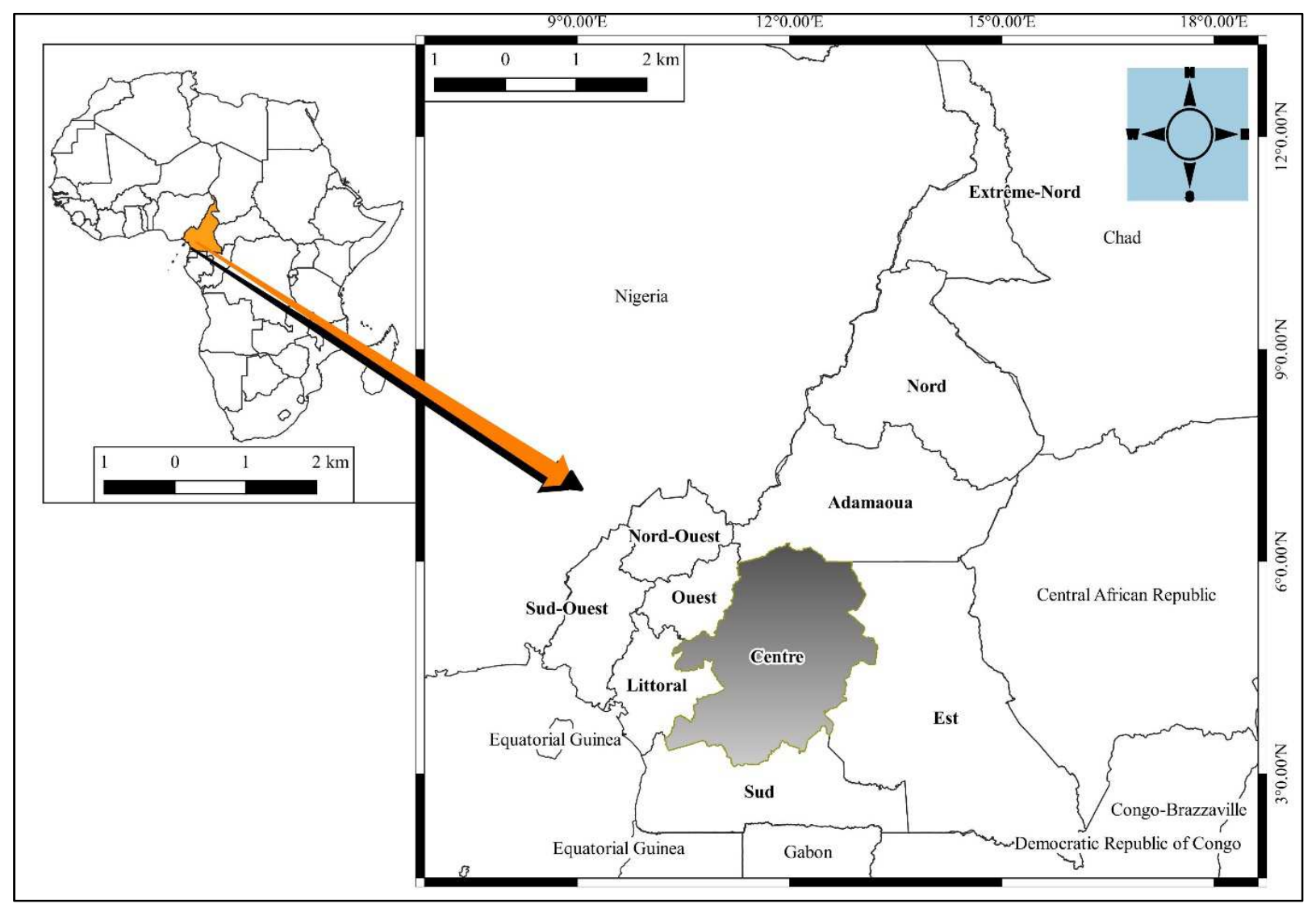

Figure 1. Location of the study area region. 


\subsection{Sampling and Analysis Technique}

The sampling technique used in this study is purposive sampling. The central region was chosen for a combination of reasons: it is the headquarters of all the agricultural advisory and support institutions in Cameroon, it is the second most populated region and the second last in terms of maize yield.

During the 2019 agricultural season, 142,957 heads of family farms were supported by the ministry in charge of agriculture in the region's ten departments. On the basis of this population, a sample size was determined using the formula:

$\mathrm{n}=(\mathrm{z})^{2} \mathrm{p}(1-\mathrm{p}) / \mathrm{d}^{2}(\mathrm{n}=$ sample size $\mathrm{z}=$ confidence level according to the reduced centred normal law (for a confidence level of $95 \%, \mathrm{z}=1.96) \mathrm{p}=$ estimated proportion of the population with characteristic $\mathrm{d}=$ margin of error tolerated [10].

Taking a population of 142,957 , a confidence level of $95 \%$ and a margin of error of $3 \%$. This means that the sample is 1,060 maize farms in the Centre region. To find the number of family farms to be analysed in each department, a proportionality coefficient $\mathrm{k}$ was calculated and applied to the number of maize producers listed in the departments by the ministry in charge of agriculture.

$$
\begin{gathered}
k=\frac{N}{n_{1}+n_{2}+\cdots n_{n}} \\
k=\frac{1060}{8350+1346+44295+73805+1686+2615+1910+798+328+7824}=0,0074
\end{gathered}
$$

This coefficient was then multiplied by the total number of producers monitored per department to obtain the number to be interviewed in each department as shown in Table 1.

Table 1. Sample of the Study

\begin{tabular}{lll}
\hline Departments & Population & Sample \\
\hline Haute Sanaga & 8350 & 62 \\
Lékié & 1346 & 10 \\
Mbam et Inoubou & 44295 & 328 \\
Mbam et Kim & 73805 & 547 \\
Mefou et Afamba & 1686 & 13 \\
Mefou et Akono & 2615 & 19 \\
Mfoundi & 1910 & 14 \\
Nyong et Kellé & 798 & 6 \\
Nyong et Mfoumou & 328 & 3 \\
Nyong et So'o & 7824 & 58 \\
Total & 142957 & 1060 \\
\hline
\end{tabular}

Prior to the administration of the questionnaires a test was carried out to correct the shortcomings of these collection tools. Once the questionnaires were fully administered, a recount was carried out, using a manual technique for classifying the questionnaires. Checks were made to ensure that the questionnaires were completed by respondents prior to analysis. The socio-economic characteristics of the IPAs and the cost-effectiveness within the maize IPAs received from these primary and also secondary sources were tabulated, coded and then processed using Microsoft Excell and SPSS version 20.0 software for statistical analysis.

These software packages made it possible to produce graphs, tables and figures, as well as averages, sums, frequencies, standard deviations and cross-tabulations.

\section{Results and Discussion}

The data after analysis made it possible to distinguish seven (07) socio-economic characteristics of family maize farms in the central region, namely: age, household size, marital status, sex, activities of the head of the farm, level of education, and land ownership.

\subsection{Age}

The average age of farmers in developing countries varies widely across studies. Most of these claims are based on data from another era due to the complexity of having them. In this study $29.9 \%$ of farm managers are over 35 years old. This percentage of young farmers in maize cultivation is in line with data from [11] analysing the 2019 report of the International Fund for Agricultural Development (IFAD) estimates that, on average, young rural people spend $50 \%$ or more of their working time on agriculture. Agriculture remains an important source of income for rural youth.

Moreover, $70.1 \%$ of the respondents are in the $36-45$, 4655 and 56-70 age groups over 70 years old. This category of farm managers can be considered as people with no other income opportunities, they are sometimes pensioners, people who have not had the opportunity to go to school and who have found the only means of poverty resilience in agriculture. Eyinga [12] also notes that more than half of the older people $(54.3 \%)$ who are economically active are mainly engaged in agricultural activities (87\%), as self-employed $(85.3 \%)$. However, these older people are in a less economically vulnerable situation than in urban areas as they are more involved in subsistence activities in order to take care of themselves on a daily basis.

\subsection{House Size}

The different proportions of size of the households of the heads of farms surveyed are shown in the figure below:

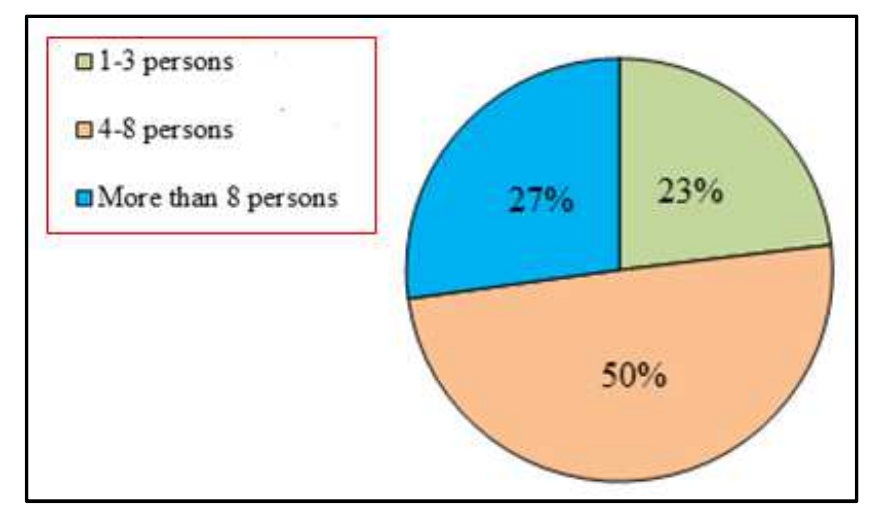

Figure 2. Different ranges of household sizes.

Figure 2 shows that $50 \%$ of the households of the heads of farms have between 4-8 people living on their roofs and $27 \%$ of the households have more than 8 people on their roofs. This high number of people per household results in 
increased pressure on natural resources, which will lead to a decrease in soil fertility. This will lead to a decrease in crop yields and thus a drop in available agricultural production, which in the long term will cause famines that will in some way restore the balance between the population and the productive capacities of the areas concerned. If the rural population increases in conditions where it reduces soil fertility, due to the pressure on available food resources, people will tend to leave the rural areas for the cities, in search of well-being in the capital Yaoundé.

\subsection{Marital Status}

Marital status can be an essential element in determining the level of control of a farm in a household. $60 \%$ of respondents are married, $33 \%$ are single, $6 \%$ are widowed and $1 \%$ are divorced.

It is possible that the percentage of married people is biased by traditional marriages, and the culture of "coming and staying" is very common in the central region. Indeed, the culture of "vient-on reste" is the fact that a man and a woman decide to live together without a marriage certificate from the civil registry office and sometimes without parental consent. Moreover, as urbanisation has swallowed up the departments close to the capital, people are increasingly turning to the departments called "la traversée" such as: Mbam and Kim, Mbam and Inoubou and sometimes Haute Sanaga to look for arable land and as a result are settling and founding families with local women without civil or traditional marriage procedures.

The percentage of single people is mostly young people who produce maize on average between 1-2 hectares with a few employees taken from the village. Most of them live in Yaoundé in the capital and only come to spend short stays on their farms to supervise their activities. These different percentages contradict the data for Cameroon as a whole, where only $20 \%$ of the population lives in households where the head of household is single [2].

\subsection{Sex}

Women are mainly responsible for post-harvest processing and food preparation and try to ensure that the varieties grown meet the needs and tastes of the household [13], in a maize farm in the central region this is even more important given the sociological position of women in this administrative unit.
During the field surveys, of the 1,060-people interviewed, 545 were women $(51.4 \%)$ and 515 were men.

During the interviews the respondents stated that maize cultivation is reserved for women who follow the cultivation activities, but the management of all the household's holdings is carried out by men.

The men take care of perennial crops such as cocoa and oil palm. The high percentage of women as heads of maize family farms is explained by the high number of respondents living without a husband (single, widowed and divorced), i.e. $40 \%$. In the absence of the man in a household, the woman takes the decisions and directs the agricultural and household activities. Furthermore, several studies, including that of Monsen [13] and Eloundou [14] provide sufficient evidence of the role of women in food crop farms where, although men control the resources, they ensure the conservation of seeds and the feeding of the household with the income from the farms. And $48.6 \%$ of the heads of the farms only give guidance, but it is the women who actually produce, they are in charge of the implementation, i.e. clearing and ploughing when it is mechanical.

\subsection{Activities of the Head of the Farm}

The rural environment is made up of a set of activities that contribute to: (i) plant, animal, fish and forestry production, (ii) the production of environmental and social services in rural areas and (iii) the sustainable management of rural areas, natural resources and the environment [15]. However, in rural areas, a number of activities linked to the main activities of rural dwellers are increasingly seen as alternative sources of income. Thus, during the survey $73.9 \%$ of respondents declared agriculture as their main activity and $13.6 \%$ declared "other" activities. These other activities refer to the trade of food, manufactured goods and motorbike transport. Kengne [16] referring to this clando or bend-skin phenomenon, said that, faced with the worsening effects of job insecurity and falling incomes, many young people, whether qualified or not, and some active workers have invested in it to ensure an income. Negligible and clandestine, transport by motorbike in landlocked areas is sometimes the only way to link certain very isolated plots of land or roads are impassable in the rainy season.

This phenomenon is so widespread that 61.5 of the farm managers interviewed have it as a secondary activity, as shown in Table 2 below.

Table 2. Main and secondary activities of maize farm managers.

\begin{tabular}{|c|c|c|c|c|}
\hline \multirow{2}{*}{ Activities } & \multicolumn{2}{|c|}{ Main activities } & \multicolumn{2}{|c|}{ Secondary activities } \\
\hline & Frequencies & Percentage (\%) & Frequencies & Percentage (\%) \\
\hline Agriculture & 783 & 73,9 & 250 & 23,6 \\
\hline Livestock & 23 & 2,2 & 110 & 10,4 \\
\hline Education & 33 & 3,1 & 17 & 1,6 \\
\hline Fishing & 9 & 0,8 & 6 & 0,6 \\
\hline Hunting & 4 & 0,4 & 14 & 1,3 \\
\hline Pupil/Student & 14 & 1,3 & 2 & 0,2 \\
\hline Defence Force Personnel & 8 & 0,8 & 2 & 0,2 \\
\hline Other & 144 & 13,6 & 652 & 61,5 \\
\hline Total & 1060 & 100 & 1060 & 100 \\
\hline
\end{tabular}




\subsection{Level of Education}

Access to education for farm managers helps to improve social status and to better participate in the life of the community, but also to better organise its exploitation. In fact, only 147 farm managers, or $13.9 \%$, declared that they had never been to school.

A study conducted by Nembot et al [17] in Cameroon makes a causal link between the availability of certain amenities and access to education, they state that the results showed that household access to electricity as a source of light increases the chances of school attendance by 7 percentage points for urban children, while in rural areas the increase is about 10 percentage points. In terms of the distance to the nearest primary school, children living in rural areas are more disadvantaged by long distances. Children living in rural areas, whose school is 2-5 kilometres from their home, lose $13.5 \%$ of their chances of attending school compared with children whose school is less than 1 kilometre away. As for children living in cities, these long distances have no influence on their schooling. This result is explained by the fact that in rural areas, the number of schools is very limited and the lack of transport penalises some children. In cities, the multiplicity of schools and the availability of transport offer many opportunities for children. This analysis adequately explains the proportions of the educational levels of the heads of farms shown in the figure above.

One possible reason for the percentage of farm managers with higher education, $4.2 \%$, is the presence of higher education institutions in 7 of the 10 departments of the central region in general, but also of agricultural training institutions.

Seventy-nine (79) respondents also indicated that they had benefited from vocational training. This was made possible thanks to the many projects and programmes initiated by the government and certain donors such as: The Programme to Support the Renovation and Development of Vocational Training in the Agriculture, Livestock and Fisheries Sectors (AFOP.); The Programme for the Promotion of Youth Agropastoral Entrepreneurship (PEA-Jeunes)

\subsection{Land Ownership}

Land ownership is crucial for agricultural production in the world in general and in Cameroon in particular, in the central region only $27.9 \%$ of the heads of farms surveyed claim to own their land, and $21.5 \%$ rent this land as shown in the table below:

Table 3. Land ownership in the central region.

\begin{tabular}{lll}
\hline Land allocation & Frequencies & Percentage (\%) \\
\hline Owner & 296 & 27,9 \\
Family & 311 & 29,3 \\
Spouse's family & 49 & 4,6 \\
Spouse & 56 & 5,3 \\
The spouse has purchased & 25 & 2,4 \\
Rental & 228 & 21,5 \\
Heritage & 58 & 5,5 \\
Other & 37 & 3,5 \\
Total & 1060 & 100 \\
\hline
\end{tabular}

In densely populated areas, "rights holders" or landowners often use their land as an asset to obtain some income through rent, and in order to defend their assets, impose different land rental models that give the tenant a precarious use status.

In addition, female heads of farms find it difficult to access land in this region, as according to tradition they cannot inherit the land, as the holders of the ancestral culture say that women are called upon to leave the village to move in with their husbands. For [18] in a survey of 1118 household in the northwest notes that women only have access to small plots through donations, family and rent.

However, the $21.5 \%$ of respondents who rent land do so from indigenous people who have customary rights to the land but whose rental principles prohibit the establishment of perennial crops. The rental system is more common in the socalled "crossing" departments, which are populated mainly by foreigners who cannot buy the land because of the reluctance of indigenous people to allow a foreigner to take over the land.

The inheritance system reported by $5.5 \%$ of respondents is based on informal recognition by traditional authorities. But alongside this tradition the legislation provides that village chiefs are liable for any purchase of land to clear the dispossession of indigenous people observed in the departments of Mfoundi and Mefou and Afamba.

\section{Conclusion}

The populations of underdeveloped countries who face several socio-economic constraints that limit the development of their farms. The ageing of the producers in the study is evidence of their inability to modernise agriculture as they no longer have sufficient strength to improve agricultural production systems. The abundance of inhabitants in households is certainly an advantage in terms of labour, but also a major hindrance to the development of family members, since the income is mainly used to feed several mouths.

Moreover, the study shows that maize is grown more for women, who are the household's nourishing udder. The women are permanently in charge of the small-scale work of food production on small plots because the men are aware that these crops are not profitable enough and therefore leave the women to look after them.

However, maize producers are characterised by their marital status, the majority are married to continue using the extra labour of the spouse, as they still believe that the abundance in the household is a source of labour to develop several areas of land for agriculture, as more than $73 \%$ have agriculture as their main activity. Strategies must therefore be sought to minimize the cost of outside labour.

Maize producers are fairly well educated, they benefit from the proximity to the headquarters of the institutions to be enlisted in the continuous and initial capacity building sessions through the specialised institutions. But these skills 
do not allow them to have sufficient strategies to access land, the difficulty of land ownership thus continues to be a hindrance to agricultural development in Cameroon.

This study makes it possible to make a recommendation to the public authorities in charge of rural development policies, namely to set up a support strategy for families involved in upstream production to reduce the hardship of their work and to provide health insurance for families with several people to feed in the household. It is also important to revise the land law to allow family farms, especially women, to own land to cultivate and feed the world.

\section{Conflict of Interest Statement}

All the authors do not have any possible conflicts of interest.

\section{Authors' Contributions}

This work was carried out in collaboration between the two authors. The author EEC designed the study, wrote the protocol, carried out the field study, managed the bibliographical research, carried out the statistical analysis and wrote the first version of the manuscript. FDE and MNJR authors designed the study and approved the protocol and the bibliographical research. Both authors read and approved the final document

\section{Consent}

The 1,060 respondents gave their verbal consent for the collection and publication of results for academic purposes only.

\section{References}

[1] Projet d'Appui au Developpement de la Microfinance Rurale (PADMIR). Etude de faisabilité de la phase 2 du PADMIR; 2016. French.

[2] Institut National de Statistique (INS). Chapitre 14: Agriculture. République du Cameroun; 2015. French.

[3] Clavel D. Savoirs et développement rural: Le dialogue au coeur de l'innovation. Domont: Corinne Thonnat; 2013. Franch.
[4] Platform for Agricultural Risk Management (PARM). Evaluation des risques agricoles au Cameroun. Rme: IRAM; 2017. French.

[5] Jeanneaux P, Blasquiet-Revol H. La Gestion des exploitations agricoles: Un état des lieux de la recherche en France. Creer et comprendre. 2012; 107: 29-40. French.

[6] Ngo Nonga F. Dynamique organisationnelle et professionnelle des exploitations familiales agricoles à base de maïs et à l'Ouest Cameroun. PCP_REPARAC; 2008. French.

[7] Minsitère de l'Agriculture et du Developpement Rural (MINADER). Publication semestrielle sur les prix des produits et intrants agricoles. Infos-prix. 2011; 01: 1-44. French.

[8] Mabah Tene G, Temple L, Havard, H. Déterminants socioéconomiques et institutionnels de l'adoption d'innovations techniques concernant la production de maïs à l'ouest du Cameroun. Tropicultura. 2013; 31 (2): 137-142. French.

[9] Projet d'Investissement et de Développement des Marchés Agricoles (PIDMA). Etats des lieux de la chaine de valeur mais au Cameroun. PIDMA; 2019. French.

[10] Kane GQ. Analyse des performances productives des exploitations familiales agricoles de la localité de Zoetele au Sud Cameroun. Thèse de DEA, Université de Soa; 2010. French.

[11] Aslihan A. Quel est l'âge moyen d'un agriculteur dans les pays en développement aujourd'hui? FIDA; 2019.

[12] Eyinga DE. Situation socio-économique des personnes âgées au Cameroun: État des lieux et facteurs explicatifs. BUCREP; 2011.

[13] Monsen JH. Gender and Development. Routledge; 2004.

[14] Eloundou EC. Analyse de l'accessibilité des femmes aux services financiers auprès des Etablissements de MicroFinances du reseau A3C. Université de Dschang; 2013. French.

[15] Ministere de l'Economie, de la Planification et de l'Amenagement du Territoire (MINEPAT) Strategie du Secteur Rural. MINEPAT; 2016.

[16] Kengne FF. Les transports clandestins autour de Yaoundé. Les cahiers d'Outre-Mer. 1985: 175-195. French.

[17] Nembot Ndeffo L, Tagne Kuelah JR, Makoudem Téné M. Determinants of Access to Education in Cameroon. African Economic Research Consortium; 2014.

[18] Fon Engwali D. Access to Arable Land by Rural Women in Cameroon. Tropicultura. 2011; 29 (2): 65-69. 